(2) Open Access Full Text Article

REVIEW

\title{
Samarium-I53-ethylene diamine tetramethylene phosphonate, a beta-emitting bone-targeted radiopharmaceutical, useful for patients with osteoblastic bone metastases
}

\author{
This article was published in the following Dove Press journal: \\ Cancer Management and Research \\ 12 August 2013 \\ Number of times this article has been viewed
}

\author{
John Longo' \\ Stephen Lutz ${ }^{2}$ \\ Candice Johnstone' \\ 'Department of Radiation Oncology, \\ Medical College of Wisconsin, \\ Milwaukee, WI, USA; '2Department \\ of Radiation Oncology, Blanchard \\ Valley Regional Cancer Center, \\ Findlay, OH, USA
}

\begin{abstract}
Bone metastases are prevalent among cancer patients and frequently cause significant morbidity. Oncology providers must mitigate complications associated with bone metastases while limiting therapy-related adverse effects and their impact on quality of life. Multiple treatment modalities, including chemotherapy, surgery, external beam radiation therapy, and radioisotopes, among others, have been recommended and utilized for palliative treatment of bone metastases. Radioisotopes such as samarium-153 are commonly used in the setting of multifocal bone metastases due to their systemic distribution, affinity for osteoblastic lesions, acceptable toxicity profile, and convenience of administration. This review focuses on samarium-153, first defining its radiobiologic and pharmacokinetic properties before describing many clinical trials that support its use as a safe and effective tool in the palliation of patients with bone metastases.
\end{abstract}

Keywords: bone metastases, pain, radiopharmaceuticals, pain flare

\section{Introduction}

Over 100,000 people develop bone metastases in the US annually. ${ }^{1}$ Certain cancers, such as those originating in the prostate, breast, lung, kidney, and thyroid, as well as multiple myeloma and melanoma, have a propensity to metastasize to bone. Bone metastases may be found in upwards of $85 \%$ of patients who die from breast, prostate, or lung cancer. ${ }^{1,2}$ Depending upon the type of underlying malignancy, presence of visceral metastasis, and overall performance status, patients may survive for extended periods with bone metastases. Bone metastases are associated with significant morbidity and mortality. Pain is the most common presenting symptom; it can be slowly progressive and focal, radicular, or referred pain. Patients with bone metastases may also experience morbidity secondary to immobility, pathologic fractures, bone marrow involvement and subsequent suppression, spinal cord compression, or other neurologic deficits.

An important objective for oncologists is to palliate symptomatic bones metastases while minimizing treatment-related side effects. There are many different modalities physicians employ to treat bony metastases, including analgesic pain medication, surgical intervention, vertebroplasty, chemotherapy, hormone therapy, bisphosphonates, external beam radiation therapy (EBRT), and radiopharmaceuticals. While the aforementioned treatment options can effectively manage symptoms related to bone metastases, the side effects, convenience, and cost of each treatment option must be weighed.
Correspondence: Stephen Lutz Department of Radiation Oncology, Blanchard Valley Regional Cancer Center, 15990 Medical Drive South, Findlay, $\mathrm{OH} 45840$, USA

$\mathrm{Tel}+$ I 4194233703

$\mathrm{Fax}+\mathrm{I} 4194270212$

Email slutz@bvha.org 
The use of bone-targeted radiopharmaceuticals, such as samarium-153 $\left({ }^{153} \mathrm{Sm}\right)$ lexidronam, is indicated for patients with pain from osteoblastic bone metastases, positive metastable technetium-99 methylene diphosphonate bone scans or fluorine-18 positron emission tomography, multifocal sites of bone pain, and analgesic-refractory pain. While EBRT remains the mainstay of treatment for localized, painful bone metastases, radiopharmaceuticals treat both symptomatic and asymptomatic bone metastases, and may have a higher therapeutic ratio than EBRT for some patients. The patients most likely to safely tolerate radiopharmaceuticals have a Karnofsky performance status (KPS) greater than 60, stable blood counts, and normal renal function. Relative contraindications for the use of radioisotopes include a solitary bone metastasis, pure osteolytic bone lesions, extensive soft-tissue metastases, current or expected pancytopenia from prior therapy, hemibody irradiation within the previous 8 weeks, acute kidney injury or chronic renal insufficiency, or disseminated intravascular coagulation. ${ }^{1,2}$

Various clinicians and bodies have sought to articulate the role of radiation therapy in treating bone metastases. In 2009, the American College of Radiology Appropriateness Criteria Expert Panel on Radiation Oncology released a policy report on therapeutic guidelines for treating bone metastases. The report stresses that palliative cancer treatment should be delivered over a short period of time in a cost-effective manner, minimize treatment-related toxicity, and enable the patient to focus on personal matters. Regarding specific palliative radiation recommendations, the report cites multiple prospective randomized trials that demonstrate that a single large fraction of radiation, typically 8 Gy in one fraction, is as effective for pain control and more efficient than prolonged radiation schedules. The report also notes that radiopharmaceuticals can be administered conveniently in an outpatient setting and show high rates of pain control for patients with multifocal bone metastases. ${ }^{3}$

The American Society of Radiation Oncology released evidence-based guidelines for palliative radiation in the setting of bone metastases in $2011 .{ }^{4}$ The guidelines note that radiopharmaceuticals are both important and underutilized for patients with multiple osteoblastic bone metastases. Radiopharmaceutical agents become especially valuable in patients who have a high number of painful sites of disease that preclude effective and safe EBRT. They encourage further study of the use of prophylactic radiopharmaceuticals and the combination of radiopharmaceuticals and other systemic agents.
The National Comprehensive Cancer Network (NCCN) has specific guidelines for metastatic castration-recurrent prostate cancer patients. ${ }^{5}$ For patients with symptomatic disease, the NCCN guidelines recommend a number of systemic agents, including a category 1 recommendation for docetaxel, palliative EBRT or radionuclide therapy, or enrollment in a clinical trial. The NCCN guidelines recommend that $800 \mathrm{cGy}$ in one fraction be utilized over a more fractionated regimen, such as 3,000 cGy in ten fractions, for nonvertebral metastases. Approved radiopharmaceuticals are appropriate for patients with widespread metastatic disease, especially if their chemotherapy options are limited, and offer the potential for significant pain relief with acceptable toxicity.

\section{Rationale for use of radiopharmaceuticals}

The normal physiologic state involves remodeling of bone by the interplay of osteoclasts that microscopically digest bone and osteoblasts that cause bone regrowth. Bone metastases cause an imbalance in bone remodeling, leading to bone overgrowth (osteoblastic metastases), bone resorption (osteoclastic metastases), or a mix of these two conditions. Radioisotopes used in the treatment of bone metastasis are typically radioactive calcium or phosphorus analogs that accumulate in areas of high bone turnover and emit low beta or gamma energy. These properties minimize adverse effects and maximize the therapeutic ratio. ${ }^{6}$ Radioisotopes deliver the radiation dose to multiple areas of osseous metastasis in a single administration and are preferentially deposited in areas of high osteoblastic activity. ${ }^{7}$ Bone metastases from prostate cancer are predominately osteoblastic, which underlies the efficacy of radiopharmaceuticals in treating widespread bone metastases in prostate cancer patients. Multiple myeloma commonly produces lytic metastases that are less responsive to radiopharmaceuticals. Most bone metastases caused by other malignancies exhibit both osteoblastic and osteolytic components.

The efficacy of radioisotopes has been widely reported. While there have been limited prospective randomized trials assessing the effectiveness of radiopharmaceuticals for bone metastases, response rates to samarium lexidronam have been reported to be between $30 \%$ and $85 \%$ of patients. The duration of pain relief with samarium lexidronam can be up to 18 months, and many studies also note concomitant decrease in analgesic use. ${ }^{8-11}$ Radiopharmaceuticals are administered intravenously in the outpatient setting with relative safety and ease, and they can be readministered for recurrent pain. 
Phosphorous-32 $\left({ }^{32} \mathrm{P}\right)$ was the first radiopharmaceutical used for palliation of painful bone metastases. ${ }^{32} \mathrm{P}$ provides excellent pain control but unacceptable hematologic toxicity. Strontium-89 $\left({ }^{89} \mathrm{Sr}\right)$ chloride and ${ }^{153} \mathrm{Sm}$ lexidronam are radiopharmaceuticals currently approved in the US and Europe for palliation of bone metastases. Rhenium-186 $\left({ }^{186} \mathrm{Re}\right)$ hydroxyethylidene diphosphonate (HEDP), ${ }^{188} \mathrm{Re}$ HEDP, and radium-223 $\left({ }^{223} \mathrm{Ra}\right.$ ) dichloride are currently under investigation. ${ }^{1,8,12,13}$

While not the focus of this review, ${ }^{223} \mathrm{Ra}$ will likely be more common in clinical practice in light of the FDA's recent approval of the radioisotope for use in patients with castrateresistant prostate cancer with symptomatic bone metastases without soft-tissue metastases. ${ }^{14} \mathrm{~A}$ calcium mimetic, ${ }^{223} \mathrm{Ra}$ dichloride emits high-energy alpha particles with an effective range of less than 100 micrometers. This is in contrast to beta emitters such as strontium and samarium, which have an effective radiation range of up to several millimeters. ${ }^{15,16}$ Nilsson et al conducted a Phase II trial randomizing men with castrate-resistant prostate cancer and bone metastases to receive weekly injections of ${ }^{223} \mathrm{Ra}(50 \mathrm{kBq} / \mathrm{kg})$ for 4 weeks versus placebo infusion. At the 24-month follow-up, $30 \%$ of the patients in the ${ }^{223} \mathrm{Ra}$ group were alive compared to $13 \%$ in the placebo group. Median overall survival was 65.3 weeks versus 46.4 weeks $(P=0.056)$ in the ${ }^{223} \mathrm{Ra}$ and placebo groups, respectively. They found no substantial differences in hematologic adverse effects between the two groups. Regarding nonhematologic adverse effects, only constipation was more commonly found in the ${ }^{223} \mathrm{Ra}$ group. ${ }^{16}$

Parker et al presented their updated findings of the Phase III, double-blind randomized Alsympca trial at the American Society of Clinical Oncology Annual Meeting in 2012. A total of 921 patients with confirmed symptomatic castrate-resistant prostate cancer with two or more bone metastases were randomized to receive ${ }^{223} \mathrm{Ra}$ at $50 \mathrm{kBq} / \mathrm{kg}$ or placebo. ${ }^{223} \mathrm{Ra}$ significantly improved overall survival, with median overall survival of 14.9 and 11.3 months for ${ }^{223} \mathrm{Ra}$ and placebo, respectively $(P=0.00007)$. Time to skeletal-related events was significantly prolonged in the ${ }^{223} \mathrm{Ra}$ compared to the placebo group (15.6 months vs 9.8 months, $P=0.00037$ ). The authors reported limited toxicity, with grade 3 or 4 neutropenia in $2.2 \%$ and thrombocytopenia in $6.3 \%$ of patients receiving ${ }^{223} \mathrm{Ra} .{ }^{17}$ The reported survival benefit of ${ }^{223} \mathrm{Ra}$ is unique among the radioisotopes historically and currently used for bone metastases. This, along with its acceptable toxicity profile, will likely impact both the timing with which ${ }^{223} \mathrm{Ra}$ is utilized during a disease course and the frequency with which it is employed.

\section{Radiobiologic properties of samarium- 53 lexidronam}

${ }^{153} \mathrm{Sm}$ has a maximum energy of $0.81 \mathrm{MeV}$ and emits both beta and gamma radiation. The mean beta energy is $0.58 \mathrm{MeV}$, and the mean gamma radiation is $103 \mathrm{keV}$. The mean range of energy deposition is $0.6 \mathrm{~mm}$, while the maximum range is $2.5 \mathrm{~mm}$. The physical half-life of ${ }^{153} \mathrm{Sm}$ is 46.3 hours ( 1.9 days). ${ }^{10,13,18}$

${ }^{153} \mathrm{Sm}_{2} \mathrm{O}_{3}$ is produced by neutron bombardment of enriched ${ }^{152} \mathrm{Sm}_{2} \mathrm{O}_{3} \cdot{ }^{153} \mathrm{Sm}_{2} \mathrm{O}_{3}$ is then dissolved into $\mathrm{HCl}$, creating ${ }^{153} \mathrm{SmCl}_{3}{ }^{7,19}$ When administered alone, ${ }^{153} \mathrm{SmCl}_{3}$ has a low propensity for uptake in the bone. Subsequently, ${ }^{153} \mathrm{SmCl}_{3}$ is chelated with ethylene diamine tetramethylene phosphonate (EDTMP). This complex accumulates in bone in association with hydroxyapatite. ${ }^{153} \mathrm{Sm}$-EDTMP has a fivefold-increased affinity for osteoblastic activity when compared with normal bone. When injected intravenously, ${ }^{153} \mathrm{Sm}$-EDTMP quickly clears the venous system, with less than $1 \%$ of the dose remaining in circulation within 1 hour of administration. Over $60 \%$ of the radioisotope is localized to bone with a high retention rate. The remainder is cleared by the kidneys and excreted in the urine within $6-8$ hours. ${ }^{10,13,18,20}$

\section{Efficacy and dosing of samarium- I 53 lexidronam}

The results of two double-blind, placebo-controlled trials demonstrating the efficacy of samarium were published by Serafini et $\mathrm{al}^{21}$ and Sartor et al. ${ }^{9}$ Serafini et al evaluated the efficacy and safety of ${ }^{153} \mathrm{Sm}$ lexidronam in a double-blind, placebo-controlled study. Eligibility criteria included patients who were at least 18 years old, had painful bone metastases, a KPS greater than or equal to 40 , and a life expectancy of at least 4 months. Eligible patients were randomized to receive 0.5 or $1.0 \mathrm{mCi} / \mathrm{kg}{ }^{153} \mathrm{Sm}$-EDTMP or placebo. The study recorded many parameters to evaluate safety and efficacy. Study participants completed a diary that started 10-14 days before the study-drug administration and continued through the duration of the study. A multisite visual analog scale (VAS) was used to arrive at a daily pain score. This information was utilized to calculate the area under the pain curve (AUPC). The participants also recorded the type and dose of all analgesic consumption, and a daily morphine-equivalent dose was calculated. Physician global assessments (PGAs) were completed at regular intervals. The treatment was unblinded at the end of 4 weeks for those without a pain response. Patients without a pain response who were randomized to receive placebo were offered $1.0 \mathrm{mCi} / \mathrm{kg}$ ${ }^{153} \mathrm{Sm}$-EDTMP if they met eligibility requirements. 
A total of 118 patients enrolled in the study. Metastatic prostate and breast cancers were the primary malignancies for $68 \%$ and $18 \%$ of patients, respectively. The three study groups shared similar pretreatment characteristics. Thirty percent of patients completed the 16 weeks of follow-up up after study-drug administration, with the majority discontinuing the study secondary to disease progression. The change from baseline in AUPC VAS was significant at each of the first 4 weeks for the group receiving $1.0 \mathrm{mCi} / \mathrm{kg}$ ${ }^{153} \mathrm{Sm}$-EDTMP $(P<0.034)$, and only significant at the first week for the group receiving $0.5 \mathrm{mCi} / \mathrm{kg}{ }^{153} \mathrm{Sm}$-EDTMP $(P=0.044)$. For the PGA, there was a significant difference between the $1.0 \mathrm{mCi} / \mathrm{kg}{ }^{153} \mathrm{Sm}-0 \mathrm{EDTMP}$ group and the placebo during each of the first 4 weeks $(P<0.016)$. There was only a significant difference between the $0.5 \mathrm{mCi} / \mathrm{kg}{ }^{153} \mathrm{Sm}$-EDTMP group and the placebo group at week $4(P=0.018)$. At week 16 , two-thirds of patients in the $1.0 \mathrm{mCi} / \mathrm{kg}{ }^{153} \mathrm{Sm}$-EDTMP group judged to be responders still reported pain relief. A significant correlation between change in baseline AUPC VAS and opioid analgesic use was only seen in the $1.0 \mathrm{mCi} / \mathrm{kg}{ }^{153} \mathrm{Sm}$-EDTMP group with a correlation coefficient of $r=0.412(P=0.01)$.

Sartor et $\mathrm{al}^{9}$ conducted a multicenter, Phase III randomized study to evaluate the efficacy of ${ }^{153} \mathrm{Sm}$-EDTMP in the palliation of painful bone metastases in hormone-refractory prostate cancer patients. Eligible patients had hormonerefractory prostate cancer, a positive bone scan with sufficient pain based on VAS score or daily morphine-dose equivalent, a KPS greater than 50, and a life expectancy of at least 4 months. Patients were randomized to receive $1.0 \mathrm{mCi} / \mathrm{kg}{ }^{153} \mathrm{Sm}$-EDTMP or placebo in a 2:1 allocation. Neither study participants nor physicians were aware of the allocation results. Study participants maintained diaries, recording pain using a VAS and a pain-descriptor scale and opioid analgesic use.

A total of 152 enrolled in the study, with 101 randomized to the group receiving $1.0 \mathrm{mCi} / \mathrm{kg}{ }^{153} \mathrm{Sm}$-EDTMP and 51 randomized to the group receiving placebo. The authors report that analgesic consumption was significantly reduced in the samarium group compared to the placebo group at weeks 3 and $4(P<0.0284)$. VAS and pain-descriptor scale scores showed significant improvement in weeks $1,2,3$, and 4 and weeks 2, 3, and 4 for the samarium group compared to the placebo group. The scores on the VAS correlated with decreased opioid use in the participants in the samarium group $(r=-0.349$, $P=0.0004)$. In summarizing their findings, Sartor et al assert that ${ }^{153} \mathrm{Sm}$-EDTMP is an effective and safe tool for managing painful bone metastases in patients with hormone-refractory prostate cancer.

Resche et al sought to elucidate the effect of two different doses of ${ }^{153} \mathrm{Sm}$ as well as evaluate the safety of administration through a multicenter, randomized, Phase II dose-controlled study. ${ }^{19}$ Eligible patients were required to have pain at one or more sites in an area overlying abnormal uptake on a bone scan, a KPS of at least 40, a life expectancy of 4 months or greater, and acceptable blood counts and renal function. The patients were randomized to receive either 0.5 or $1.0 \mathrm{mCi} / \mathrm{kg}$ ${ }^{153} \mathrm{Sm}$-EDTMP. Physicians were aware of the dose each patient received. Study participants were monitored for up to 16 weeks after study drug administration. After 6 hours of administration, a urine specimen was collected, and a bone scan was obtained within 24-72 hours. Participants recorded pain levels using a VAS in addition to assessing their daily level of discomfort and answering whether or not the drug improved their pain on a weekly basis. Daily pain levels from the diaries were used to calculate AUPC scores. Additionally, participants rated sleep characteristics and documented their use of analgesic medications. PGAs were completed by a physician at regular intervals.

A total of 114 patients participated in the study; 55 patients were randomized to the group receiving $0.5 \mathrm{mCi} / \mathrm{kg}{ }^{153} \mathrm{Sm}$-EDTMP, and 59 received $1.0 \mathrm{mCi} / \mathrm{kg}$ ${ }^{153} \mathrm{Sm}$-EDTMP. The most common malignancy was prostate cancer followed by breast cancer. Fifty-four percent of patients in the higher-dose group and $44 \%$ of patients in the lower-dose group completed the 16-week study. Increased pain, death, and disease progression were the most common reasons for study discontinuation. Statistically significant reductions in baseline pain were noted at weeks 3 and 4 for participants in the higher-dose group $(P<0.005)$. There were no statistically significant reductions in baseline pain for patients in the lower-dose group in weeks 1-4. A significant difference between the lower- and higher-dose groups was noted at week $4(P=0.0476)$. Regarding the assessment of daytime discomfort, a significant decrease from baseline daytime discomfort was only found in participants in the higher-dose group in weeks 3 and $4(P<0.011)$. Participants in the higher-dose group had a significant improvement in sleep compared to baseline in week $4(P=0.026)$. No statistically significant changes from baseline opioid analgesic use were observed in either dose group. As mentioned, physicians were aware of the dose that participants were receiving. The study reports that physicians assessed 55\% of participants in the $0.5 \mathrm{mCi} / \mathrm{kg}{ }^{153} \mathrm{Sm}$-EDTMP group and $70 \%$ of participants in the $1.0 \mathrm{mCi} / \mathrm{kg}{ }^{153} \mathrm{Sm}-\mathrm{EDTMP}$ group 
to be treatment responders at week 4. A durable degree of pain relief was reported by physicians at 16 weeks in $39 \%$ of participants randomized to the higher-dose group and 31\% randomized to the lower-dose group. Resche et al purported that their findings confirmed the efficacy and safety of the $1.0 \mathrm{mCi} / \mathrm{kg}$ dose of ${ }^{153} \mathrm{Sm}$-EDTMP.

A multicenter, Phase II trial out of the People's Republic of China randomized 105 patients with painful bone metastases to receive $37 \mathrm{MBq} / \mathrm{kg}(1 \mathrm{mCi} / \mathrm{kg})$ or $18.5 \mathrm{MB} / \mathrm{kg}$ $(0.5 \mathrm{mCi} / \mathrm{kg}){ }^{153} \mathrm{Sm}$-EDTMP. ${ }^{11}$ Interestingly, 41 trial participants had underlying lung cancer and 15 had esophageal cancer, whereas only 14 and twelve had breast and prostate cancer, respectively. Sum of the effect product was calculated based on study participants' pain scores and was utilized to assess response to therapy. The authors reported a positive pain response in $83.8 \%$ of patients, independent of dose. The duration of this pain response lasted between 3 and 16 weeks.

\section{Other trials (repeat dosing or with concurrent docetaxel)}

Sartor et al conducted a multicenter, open-label study to evaluate the efficacy and safety of repeat administration of ${ }^{153} \mathrm{Sm}$-EDTMP. ${ }^{22}$ Patients who met eligibility criteria for the initial ${ }^{153} \mathrm{Sm}$-EDTMP administration were eligible for repeat administration if they experienced pain response by week 4 after first dose administration and experienced recurrent pain by week 8 . Pain was assessed at baseline at weeks 4 and 8 using the Brief Pain Inventory. A total of 202 patients enrolled in this study, the majority of whom had prostate cancer. Significant decreases in pain scores were observed at week 4 after each of the first three dose infusions and at week 8 during the first two infusions. Decreases in pain scores were noted in 70\%,63\%, and $80 \%$ of patients at week 4 after the first, second, and third administrations, respectively. Sartor et al describe their results as supporting the use of repeated doses of ${ }^{153} \mathrm{Sm}$-EDTMP to palliate painful bony metastases successfully.

Fizazi et al assessed the effect of combined docetaxel and samarium as consolidation therapy for patients undergoing palliative treatment for castration-resistant prostate cancer in a Phase II prospective trial. ${ }^{23}$ Eligible patients who experienced a response or disease stabilization after four cycles of docetaxel and estramustine were given consolidation docetaxel $\left(20 \mathrm{mg} / \mathrm{m}^{2} \times 6\right.$ weeks $)$ and ${ }^{153} \mathrm{Sm} 37 \mathrm{MBq} / \mathrm{kg}$ ( $1 \mathrm{mCi} / \mathrm{kg}$ ) during week 1 . The primary end point was prostate-specific antigen (PSA) progression-free survival (PFS). Secondary end points included PSA response, pain response, toxicity, and overall survival.
Forty-three patients participated in the trial; 95\% received the full four cycles of induction chemotherapy, while $81 \%$ received at least five of six planned weekly consolidation docetaxel infusions. Of this $81 \%$, all received the $37 \mathrm{MBq} / \mathrm{kg}$ ( $1 \mathrm{mCi} / \mathrm{kg})$ dose of ${ }^{153} \mathrm{Sm}$-EDTMP.

The median PSA PFS was 6.4 months. PSA response rates were $72 \%$ after induction and $64 \%$ after consolidation chemotherapies. Seventy-two percent of patients who received consolidation chemotherapy had a greater than $20 \%$ decrease in pain from their baseline level. The median overall survival rate was 29 months. The authors conclude that the docetaxel and ${ }^{153} \mathrm{Sm}$-EDTMP regimen used as consolidation in patients with bone metastases from castrationresistant prostate cancer is associated with a high biologic and symptomatic response rate, prolonged survival, adequate pain control, and acceptable adverse effects.

Lin et al conducted a nonrandomized, open-label, Phase I study to assess the efficacy and safety of two cycles of ${ }^{153} \mathrm{Sm}$-EDTMP with escalating doses of docetaxel in patients with castration-resistant prostate cancer and painful bone metastases. ${ }^{24}$ Eligible patients were assigned to cohorts with different numbers and doses of docetaxel. ${ }^{153} \mathrm{Sm}$-EDTMP $1.0 \mathrm{mCi} / \mathrm{kg}$ was administered on day 2 of each cycle, with a maximum number of two cycles, each cycle lasting 12 weeks. A pain score was calculated based on the type and dose of analgesic. Serum PSAs and bone scans were obtained at regular intervals. Thirteen patients received an average of 3.6 doses of docetaxel and 1.5 doses of ${ }^{153} \mathrm{Sm}$. One-hundred percent of the six patients with pain scores greater than or equal to 2 had a pain score that decreased from baseline during treatment. Eight of thirteen patients had a decrease in PSA of greater than $50 \%$. The authors conclude that their study shows that concurrent 6-month administration of 4 doses of standard docetaxel $\left(75 \mathrm{mg} / \mathrm{m}^{2}\right)$ with 2 infusions of $1 \mathrm{mCi} / \mathrm{kg}$ of ${ }^{153} \mathrm{Sm}$ at 3-month intervals is feasible and warrants further study.

Morris et al sought to characterize the safety profile better for the use of escalating doses of both docetaxel and ${ }^{153} \mathrm{Sm}-$ EDTMP for men with castration-resistant metastatic prostate cancer. ${ }^{25}$ Eligible patients were randomized to six different cohorts that varied by dose of docetaxel $\left(60-75 \mathrm{mg} / \mathrm{m}^{2}\right)$ and samarium $(0.5-1.0 \mathrm{mCi} / \mathrm{kg})$. The primary end point of the study was safety, but Morris et al also evaluated antitumor activity on the basis of PSA and imaging studies. Twentyeight patients were assigned to six cohorts. The authors reported that 15 of 26 patients had greater than $50 \%$ PSA decline while on study.

A recent Cochrane review showed that there was no measurable difference in efficacy between ${ }^{153} \mathrm{Sm}$-EDTMP 
and other radiopharmaceuticals, such as ${ }^{89} \mathrm{Sr},{ }^{186} \mathrm{Re}$, and ${ }^{32} \mathrm{P} .{ }^{26}$ Pain flares were not common in patients receiving radiopharmaceuticals, based upon available data. The authors were warier of hematologic toxicity due to these types of agents than were those who carried out previous reviews.

${ }^{153} \mathrm{Sm}$ has also been used, albeit with less frequency, in osteosarcoma. Osteosarcoma is a relatively radioresistant malignancy with limited disease control at doses of $<60 \mathrm{~Gy}$. EBRT doses of $>60$ Gy are associated with significant normal-tissue adverse effects. ${ }^{27}$ The use of ${ }^{153} \mathrm{Sm}$-EDTMP has been investigated as a way to deliver effective doses to metastatic osteosarcoma lesions while circumnavigating normal structure toxicity. ${ }^{153} \mathrm{Sm}$ has been used at much higher doses in osteosarcoma than seen with its use in osteoblasticpredominant metastatic cancers. Anderson et al studied the use of escalating doses of ${ }^{153} \mathrm{Sm}-\mathrm{EDTMP}(1.0-30 \mathrm{mCi} / \mathrm{kg})$ followed by peripheral blood progenitor cell (PBPC) or marrow support in patients with bone metastases or osteosarcoma metastases. Patients received autologous PBPCs or marrow on day 14 following ${ }^{153} \mathrm{Sm}$-EDTMP injection. The authors found that aside from transient hypocalcemia and an increased incidence of initial pain flare, high-dose ${ }^{153}$ Sm-EDTMP was not associated with significant nonhematologic side effects. All high-dose ${ }^{153} \mathrm{Sm}$-EDTMP patients experienced grade 2-4 anemia, leukopenia, and thrombocytopenia. Recovery of hematopoiesis was only problematic in two patients receiving the $30 \mathrm{mCi} / \mathrm{kg}$ dose, with an inadequate number of stem cells infused at day 14. In light of acceptable toxicity, the authors concluded that such findings warranted further investigation of high-dose ${ }^{153} \mathrm{Sm}$-EDTMP with PBPC support in controlling pain and improving PFS and overall survival. ${ }^{27}$

Berger et al published the results from a retrospective review of a multicenter study in which patients with biopsy-proven high-grade osteosarcoma with metachronous metastases received doses of ${ }^{153} \mathrm{Sm}$-EDTMP ranging from $3 \mathrm{mCi} / \mathrm{kg}$ to $30 \mathrm{mCi} / \mathrm{kg}$ followed by hematopoietic stem cell rescue. While they reported no treatment-related deaths or life-threatening nonhematologic toxicity, they found PFS to be limited: $32 \%$ and $9 \%$ at 4 and 6 months, respectively. Additionally, minimal pain relief was reported with $6 \%$ of patients at 1 week, $56 \%$ of patients at 2 weeks, and no patients at 4 months. Subsequently, Berger et al concluded that there was minimal advantage of high-dose ${ }^{153} \mathrm{Sm}$-EDTMP administration followed by hematopoietic stem cell rescue for patients with metastatic osteosarcoma. ${ }^{28}$ The use of ${ }^{153} \mathrm{Sm}$ in osteosarcoma and other sarcomas with a propensity for bone metastases remains an area of research interest.

\section{Toxicity}

Historically, one of the benefits of ${ }^{153}$ Sm-EDTMP was thought to be its limited toxicity profile. Prior to its use in humans, multiple clinical trials evaluated the pharmacokinetics and toxicity of ${ }^{153} \mathrm{Sm}$-EDTMP in animals. ${ }^{29,30}$ Singh et al sought to better characterize the human pharmacokinetics by injecting five patients with histopathologically confirmed cancer with bone metastases with $2 \mathrm{mCi} / \mathrm{kg}{ }^{153} \mathrm{Sm}$-EDTMP. The biodistribution of ${ }^{153} \mathrm{Sm}$-EDTMP was determined by obtaining whole-body planar scintigraphic images, blood clearance, and 24-hour urine clearance. As surrogates for systemic toxicities, the group obtained pre- and postadministration vitals and lab values. The authors found high lesion uptake of ${ }^{153} \mathrm{Sm}$-EDTMP, with a mean lesion-to-bone ratio of $4.04 \pm 2.62 .{ }^{153} \mathrm{Sm}$-EDTMP cleared the plasma rapidly via the urinary system. Approximately $2 \%$ of the ${ }^{153} \mathrm{Sm}$-EDTMP remained in the plasma 4 hours after injection, and half of the dose was excreted in the urine within 6-7 hours. Pre- and postadministration vital signs remained concordant, and there were no changes between pre- and postadministration hematologic profiles, serum chemistries, or urinalyses. Singh et al advocated therapeutic trials on the basis of their results. ${ }^{31}$

Farhanghi et al conducted a follow-up trial to describe the toxicity and therapeutic results of escalating doses of ${ }^{153} \mathrm{Sm}$-EDTMP $(0.1-1.0 \mathrm{mCi} / \mathrm{kg})$ in 22 patients with painful bone metastases. Radiopharmacokinetic information was determined by obtaining postadministration plasma and urine specimens and total-body scintigraphy. The authors assessed toxicity by obtaining weekly postinfusion labs and pain response through patient pain diaries. Like Singh et al, Farhanghi et al reported rapid clearance of plasma radioactivity $(1.3 \% \pm 0.7 \%$ at 4 hours $)$ and urinary excretion of $35 \% \pm 13.5 \%$ at 24 hours. Rapid plasma clearance was directly proportional to skeletal uptake. Thrombocytopenia was seen in patients receiving $\geq 0.35 \mathrm{mCi} / \mathrm{kg}$, with platelet nadirs occurring at a median of 28 days before returning to baseline. Leukopenia was seen in patients receiving $\geq 0.75 \mathrm{mCi} / \mathrm{kg}$, with recovery to pretreatment levels between 6 and 8 weeks. Nonhematologic toxicity was limited to transient pain flares in some patients, with no reported cardiovascular, respiratory, renal or hepatic adverse effects or electrolyte abnormalities. Additionally, the authors reported pain palliation in $65 \%$ of evaluable patients, concluding that ${ }^{153} \mathrm{Sm}$-EDTMP at doses of $0.5-1.0 \mathrm{mCi} / \mathrm{kg}$ is safe and effective in the majority of patients with painful bone metastases. ${ }^{32}$

Collins et al conducted a Phase I/II dose-escalation trial to determine the maximum tolerated dose (MTD) of ${ }^{153} \mathrm{Sm}$-EDTMP in patients with prostate cancer with 
bone metastases. Fifty-two patients were enrolled and divided into groups of four. The first group received ${ }^{153} \mathrm{Sm}$-EDTMP $1.0 \mathrm{mCi} / \mathrm{kg}$, and the dose was escalated by $0.5 \mathrm{mCi} / \mathrm{kg}$ per group until the predetermined MTD was reached (grade 3 or greater toxicity observed in two of four patients in a group). The MTD was determined to be $2.5 \mathrm{mCi} / \mathrm{kg}$, with two of four patients in the $3.0 \mathrm{mCi} / \mathrm{kg}$ group experiencing grade 3 or greater neutropenia. Increasing dose levels showed increasing hematologic toxicity, but no patient demonstrated neutropenic fever, infection, or hemorrhage. Eighty-seven percent of patients had hematologic recovery. ${ }^{33}$

These studies and others precipitated the Phase II/III trials that have better defined both the therapeutic effect and importantly the toxicity profile of ${ }^{153} \mathrm{Sm}$-EDTMP as used in today's clinical setting.

As noted, the most common clinically significant side effects include short-term pain flare and decreased blood counts weeks after administration due to generalized bone marrow suppression. Pain flare usually occurs within the first 24-48 hours after the dose is given. While this toxicity has not been well studied, it appears to be uncommon. Resche et al reported pain flares following ${ }^{153} \mathrm{Sm}$-EDTMP administration in $8 \%-11 \%$ of patients. ${ }^{19}$ The pain flares tend to be transient, and are amenable to short-term increases in narcotic analgesics or coadministration with steroids or nonsteroidal anti-inflammatory medications.

The hematologic effects of samarium are potentially more severe and may prove dose-limiting, especially in patients with preexisting bone marrow suppression. ${ }^{153} \mathrm{Sm}$-EDTMP administration impacts platelets and leukocytes, leading to thrombocytopenia and leukopenia. Anemia was not associated with ${ }^{153} \mathrm{Sm}$-EDTMP alone. The median time to platelet and leukocyte nadirs in a number of trials was 3-5 weeks after administration, with platelet and leukocyte counts returning to baseline by 8 weeks. Various studies reported a limited number of grade 3 and 4 hematologic toxicities. ${ }^{9,19-21}$ In their Phase II study of repeated doses of ${ }^{153} \mathrm{Sm}$-EDTMP, Sartor et al noted that the frequency and severity of hematologic adverse effects were similar to those reported with a single administration. ${ }^{22}$ Concurrent administration of ${ }^{153} \mathrm{Sm}$-EDTMP with docetaxel was associated with increased hematologic toxicity. Both Lin et al and Morris et al reported instances of grade 3 and 4 neutropenia. Lin et al also reported episodes of dose-limiting thrombocytopenia. ${ }^{24}$ The respective studies found that the hematologic toxicity was largely reversible. Other nonhematologic side effects are limited and their association with ${ }^{153} \mathrm{Sm}$-EDTMP unclear. They included nausea, vomiting, constipation, fever, anorexia, spinal cord compression, dyspnea, and urinary tract infection. ${ }^{2}$

\section{Conclusion}

Bone metastases are a common manifestation of malignancy that can cause significant morbidity. While there are many palliative treatment options for patients with painful bone metastases, radiopharmaceuticals such as ${ }^{153} \mathrm{Sm}$-EDTMP have demonstrated efficacy with acceptable toxicity when used to treat symptomatic, predominantly osteoblastic metastatic bone lesions. ${ }^{153} \mathrm{Sm}$-EDTMP may even be safely and effectively administered in retreatment for patients with recurrent pain. Current data regarding the use of ${ }^{153} \mathrm{Sm}$-EDTMP in conjunction with bisphosphonates and chemotherapy remain weak. Future trials will undoubtedly further define the potential benefits of ${ }^{153} \mathrm{Sm}$-EDTMP and other radioisotopes. Based on the clinical trials and current guidelines, ${ }^{153} \mathrm{Sm}$ is an effective, safe, and potentially underutilized treatment option for patients with osteoblastic bone metastases. The use of bone-seeking radiopharmaceuticals such as ${ }^{153} \mathrm{Sm}$ EDTMP in conjunction with chemotherapy is an evolving field. Docetaxel is the agent that has been studied the most. Future clinical trials will further define additional beneficial applications of bone-targeted radiopharmaceuticals.

\section{Disclosure}

The authors have no conflicts of interest to disclose.

\section{References}

1. Hartsell WF, Yajnik S. Palliation of bone metastases. In: Halperin EC, Perez CA, Brady LW, et al, editors. Perez and Brady's Principles and Practice of Radiation Oncology, 5th ed. Philadelphia: Lippincott Williams \& Wilkins; 2008:1986-1999.

2. Sartor O. Overview of samarium-153 lexidronam in the treatment of painful metastatic bone disease. Rev Urol. 2004;6 Suppl 10:S3-S12.

3. Janjan N, Lutz ST, Bedwinek JM, et al. Therapeutic guidelines for the treatment of bone metastasis: a report from the American College of Radiology Appropriateness Criteria Expert Panel on Radiation Oncology. $J$ Palliat Med. 2009;12(5):417-426.

4. Lutz S, Berk L, Chang E, et al. Palliative radiotherapy for bone metastases: an ASTRO evidence-based guideline. Int $J$ Radiat Oncol Biol Phys. 2011;79(4):965-976.

5. National Comprehensive Cancer Network (NCCN). NCCN Clinical Practice Guidelines in Oncology - prostate cancer. Version 2. Available from: http://www.nccn.org/professionals/physician_gls/__guidelines.asp Accessed July 1, 2013.

6. Bauman G, Charette M, Reid R, Sathya J. Radiopharmaceuticals for the palliation of painful bone metastasis: a systemic review. Radiother Oncol. 2005;75(3):258-270.

7. Chiacchio S, Mazzarri S, Lorenzoni A, et al. Radionuclide therapy and integrated protocols for bone metastases. Q J Nucl Med Mol Imaging. 2011;55(4):431-447.

8. Finlay IG, Mason MD, Shelley M. Radioisotopes for the palliation of metastatic bone cancer: a systematic review. Lancet Oncol. 2005;6(6):392-400. 
9. Sartor O, Reid RH, Hoskin PJ, et al. Samarium-153-lexidronam complex for treatment of painful bone metastases in hormone-refractory prostate cancer. Urology. 2004;63(5):940-945.

10. McEwan AJ. Use of radionuclides for the palliation of bone metastases. Semin Radiat Oncol. 2000;10(2):103-114.

11. Tian JH, Zhang JM, Hou QT, et al. Multicentre trial on the efficacy and toxicity of single-dose samarium-153-ethylene diamine tetramethylene phosphonate as a palliative treatment for painful skeletal metastases in China. Eur J Nucl Med. 1999;26(1):2-7.

12. Vengalil S, O’Sullivan JM, Parker CC. Use of radionuclides in metastatic prostate cancer: pain relief and beyond. Curr Opin Support Palliat Care. 2012;6(3):310-315.

13. Class R, Jost M, Mose S, et al. Radioimmunoglobulins and nonsealed radionuclide therapy. In: Halperin EC, Perez CA, Brady LW, et al, editors. Perez and Brady's Principles and Practice of Radiation Oncology, 5th ed. Philadelphia: Lippincott Williams \& Wilkins; 2008: 583-598.

14. National Cancer Institute. FDA approval for radium 223 dichloride. 2013. Available from: http://www.cancer.gov/cancertopics/druginfo/ fda-radium-223-dichloride. Accessed June 15, 2013.

15. Nilsson S, Strang B, Aksnes AK, et al. A randomized, dose-response, multicenter phase II study of radium-223 chloride for the palliation of painful bone metastases in patients with castration-resistant prostate cancer. Eur J Cancer. 2012;48(5):678-686.

16. Nilsson S, Franzén L, Parker C, et al. Two-year survival follow-up of the randomized, double-blind, placebo-controlled phase II study of radium-223 chloride in patients with castration-resistant prostate cancer and bone metastases. Clin Genitourin Cancer. 2013;11(1):20-26.

17. Parker C, Nilsson S, Heinrich D, et al. Updated analysis of the phase III, double-blind, randomized, multinational study of radium-223 chloride in castration-resistant prostate cancer (CRPC) patients with bone metastases (ALSYMPCA). J Clin Oncol. 2012;30 Suppl:LBA4512.

18. Eary J, Collins C, Stabin M, et al. Samarium-153-EDTMP biodistribution and dosimetry estimation. J Nucl Med. 1993;34(7):1031-1036.

19. Resche I, Chatal JF, Pecking A, et al. A dose-controlled study of $153 \mathrm{Sm}$ ethylenediaminetetramethylenephosphonate (EDTMP) in the treatment of patients with painful bone metastases. Eur J Cancer. 1997;33(10): 1583-1591.

20. Serafini AN. Samarium Sm-153 lexidronam for the palliation of bone pain associated with metastases. Cancer. 2000;88(Suppl 12): 2934-2939.

21. Serafini AN, Houston SJ, Resche I, et al. Palliation of pain associated with metastatic bone cancer using samarium-153 lexidronam: a doubleblind placebo-controlled clinical trial. J Clin Oncol. 1998;16(4): 1574-1581.
22. Sartor O, Reid RH, Bushnell DL, Quick DP, Ell PJ. Safety and efficacy of repeat administration of samarium Sm-153 lexidronam to patients with metastatic bone pain. Cancer. 2007;109(3):637-643.

23. Fizazi K, Benzeboc P, Lumbroso J, et al. Phase II trial of consolidation docetaxel and samarium-153 in patients with bone metastases from castration resistant prostate cancer. J Clin Oncol. 2009;27(15): 2429-2435

24. Lin J, Sinibaldi VJ, Carducci MA, et al. Phase I trial with a combination of docetaxel and ${ }^{153} \mathrm{Sm}$-lexidronam in patients with castration-resistant metastatic prostate cancer. Urol Oncol. 2009;29(6):670-675.

25. Morris MJ, Pandit-Taskar N, Carrasquillo J, et al. Phase I study of samarium-153 lexidronam with docetaxel in castration-resistant metastatic prostate cancer. J Clin Oncol. 2009;27(15):2436-2442.

26. Roqué I Figuls M, Martinez-Zapata MJ, Scott-Brown M,Alonso-Coello P. Radioisotopes for metastatic bone pain. Cochrane Database Syst Rev. 2011;(7):CD003347.

27. Anderson PM, Wiseman GA, Dispenzieri A, et al. High dose samarium153 ethylene diamine tetramethylene phophonate: low toxicity of skeletal irradiation in patients with osteosarcoma and bone metastases. J Clin Oncol. 2002;20(1):189-196.

28. Berger M, Grignani G, Giostra A, et al. ${ }^{153}$ Samarium-EDTMP administration followed by hematopoietic stem cell support for bone metastases in osteosarcoma patients. Ann Oncol. 2012;23(7): 1899-1905.

29. Lattimer JC, Corwin LA, Stapleton J, et al. Clinical and clinicopathologic effects of samarium-153-EDTMP administered intravenously to normal beagle dogs. J Nucl Med. 1990;31(5):586-593.

30. Lattimer JC, Corwin LA, Stapleton J, et al. Clinical and clinicopathologic response of canine bone tumor patients to treatment with samarium-153-EDTMP. J Nucl Med. 1990;31(8):1316-1325.

31. Singh A, Holmes RA, Farhangi M, et al. Human pharmacokinetics of samarium-153 EDTMP in metastatic cancer. J Nucl Med. 1989;30(11): 1814-1818.

32. Farhanghi M, Holmes RA, Volkert WA, Logan W, Singh Amolak. Samarium-153-EDTMP: pharmacokinetic, toxicity and pain response using an escalating dose schedule in treatment of metastatic bone cancer. J Nucl Med. 1992;33(8):1451-1458.

33. Collins C, Eary JF, Donaldson G, et al. Samarium-153-EDTMP in bone metastases of hormone refractory prostate carcinoma: a phase I/II trial. J Nucl Med. 1993;34(11):1839-1844.
Cancer Management and Research

\section{Publish your work in this journal}

Cancer Management and Research is an international, peer-reviewed open access journal focusing on cancer research and the optimal use of preventative and integrated treatment interventions to achieve improved outcomes, enhanced survival and quality of life for the cancer patient. The journal welcomes original research, clinical \& epidemiological

\section{Dovepress}

studies, reviews \& evaluations, guidelines, expert opinion \& commentary, case reports \& extended reports. The manuscript management system is completely online and includes a very quick and fair peerreview system, which is all easy to use. Visit http://www.dovepress.com/ testimonials.php to read real quotes from published authors. 